\title{
Desktop VR as a Virtual Workspace: a Cognitive Aspect
}

\section{Borbála Berki}

Széchenyi István University, Multidisciplinary Doctoral School of Engineering Sciences; Egyetem tér 1, H-9026 Győr, Hungary

berki.borbala@sze.hu

\begin{abstract}
This paper explores the benefits of using a desktop VR as a virtual workspace. Forty-nine participants data included in this study. With a between-subjects design, we compared the use of extra information between a desktop VR (23 people) and a web browser (26 people). Their tasks were to solve numerical tasks and write the results in a separate spreadsheet. They could follow their performance (solved task / all tasks) on a graph. Then, they filled out a questionnaire where they had to estimate their performance, and indicate the source of this estimation (the only valid source was the provided graph). In the subsample of those who used the graph, the members of the VR group estimated significantly more accurately their performance than the members web browser group. Therefore, the $3 D$ desktop VR workspace can provide benefits to its users by displaying extra information permanently.
\end{abstract}

Keywords: desktop VR; MaxWhere; virtual workspace

\section{Introduction}

Nowadays we are surrounded by different screens of all sizes from the tiny smartwatches to large high-resolution displays. It is part of our everyday routine to interact with them in different manners for different aims. Human-computer interaction (HCI) researches, designs, implements and evaluates the interfaces between human users and computers. The aim is to enable an easy and efficient way of communication. For this HCI uses the knowledge of cognitive and social psychology, linguistics, communication theory, graphic and industrial design. [1]

Cognitive infocommunications (CogInfoCom) is a much wider field which focuses on cognitive capabilities (instead of focusing merely on interaction). Not only on the human cognitive capabilities but in a more generic perspective which subsumes both natural and artificial components. Thus, human mental capabilities can take the advantage, which is more and more important as the role and value of information is constantly increasing [2, 3]. Such an advantage could be that the 
human brain and its capacities are extended through infocommunication devices which enables a more effective interaction. This includes a wide variety of devices and solutions from brain-computer interfaces to educational applications of VR [4, $5,6,7,8,9,10,11,12]$.

\subsection{Virtual Workspaces}

With the spread of personal computers, the screen size has become an impediment. The users want to manipulate and look at more and more pieces of information, but these are fragmented in different windows. To solve this, users start to switch back and forth between activities that are part of the same project [13]. Card and Henderson compare it with the classic method of working with papers: on a large desk every document is grouped and arranged meaningfully to enable an effective workflow. The visual availability of the papers helps organize the task, as they become memory cues. Besides the size of the screen, another benefit of the usage of papers is that there is no need to assign names or formal codes to the grouped documents. This is inevitable on computers to make an effort to add meaningful names to documents. To solve this problem and enlarge the user's screen, different techniques have arisen. The most commons are alternating screen usage, distorted views, large virtual workspaces and multiple virtual workspaces [14].

Real-time, synchronous collaboration rely on tools such as video or audio conferencing and instant messaging. Integrate these session-centric and the document-centric collaboration tools in one system was an early objective in the design of virtual workspaces. [15]. With the advance of technology, media richness has augmented. This means that an audioconference could convey more cues (tone, pauses) than an e-mail, which reduces the possibility of misunderstanding [16]. Widely used workspace technologies are electronic whiteboard, collaborative document editors, instant messaging applications, calendar and common repository [17]. Beyond these tools, the knowledge sharing, and the coordination of tasks are essentials for adequate functioning of a collaborative virtual team. Situational awareness is the awareness of the here-andnow states of collaborating team members, which helps them in the planning of the subsequent task. The situational awareness can be facilitated through virtual co-presence, which means that individuals feel as if they are in the same room with the others. This shared context also helps the knowledge exchange [18].

Maintaining focus and keeping the user in the context of her reasoning process is a basic requirement of a good computer-based workstation. Direct interaction and manipulation help to stay in the cognitive zone of the task, which means that it does not interrupt the workflow thus, it remains one cognitive whole. Also, avoiding actions that take the user outside of the frame of the task, for example, menus especially the traditional pull-downs where users have to sort through and 
think about each item, is a way to help to remain focused [19]. One of the most widely known metaphors in the field of HCI is the aforementioned desktop metaphor. Metaphors help to understand unfamiliar processes and places, with the help of a well-known situation. But with the virtual reality, there is no need for metaphor because it is exactly an environment. Thus, users can directly interact with the virtuality, without the help of a metaphor [20].

The strong need to have an overview is another phenomenon which suggests the use of VR. This need is observed even with the use of large, high-resolution displays, where users have stood or sat back at a distance that allowed them to view the entire display at once [21]. On the grounds of these, virtual reality can be an answer to many challenges, such as: situational awareness, task switching on a small screen and integrating session- and document-centric tools.

\subsection{Desktop Virtual Reality}

The term virtual reality is in a continuous change since its appearance in the 1960s. VR means a computer-generated 3D environment where the user can interact in real-time. There is a huge variety of virtual environments, from fully immersive (HMD - Head-Mounted Displays, CAVE) to non-immersive desktop versions [22]. HMD provides an intuitive and natural interaction, but it can cause discomfort and eye strain [23]. Better performance in the desktop VR was also observed, despite the personal impression of effectiveness in HMD VR [24]. Desktop or non-immersive VR is the newest and simplest form of VR where a high-resolution panoramic image is displayed on a standard desktop computer. Users employ a mouse or keyboard to move and explore the virtual environment. Different movements are used in order to simulate physical movements of the head and the body: rotating the image, or zooming in and out to imitate movements toward and away from objects. In the virtual scene, interactive objects are embedded, which can be manipulated, picked up, rotated or activated. With the help of clickable "hotspots" standard video and audio clips, documents or doorways to other VR spaces are also embedded [22, 25, 26].

The use of desktop VR requires only a short training session there is no need for extensive prior training. More experienced computer gamers can have some advantage [27] in navigation. Some research showed gender differences in spatial orientation and navigation in contextually unfamiliar, visually and navigationally complex virtual environments with technical contents. In these settings, male users are more confident and outperform female participants [22, 27]. Other studies showed that learners with lower spatial ability could benefit more from the VR learning mode [28]. 


\subsection{Overview of the Current Research}

As shown earlier a desktop virtual reality can meet the aforementioned requirements of an effective virtual workspace. It enables the user to stay in the workflow by direct manipulation of different types of information. The 3D layout can provide insights into documents which are not in the focus, but due to the perspective, they appear in the visual field. Can this kind of extra information provide further benefits to the user? Do they remember of supplementary information displayed in their visual field?

A between-subjects design was used to investigate this question. Either group worked with a desktop VR and the other with a basic web browser. As a desktop VR, the MaxWhere Virtual Environment [29] was used. This VR engine can load webpages on the so-called smartboards inside of a 3D environment. The smartboards have a predefined location within a space and the user can load the desired webpages, documents, web applications on them. As a web browser, Google Chrome [30] was used because it is the most frequently used web browser in Hungary [31].

The experimental task required to use three webpages with different content. This is a quite limited number as in the most cases much more document is used simultaneously. But this experiment wants to measure the differences in a simpler task with such a few numbers of documents. One document was a simple webpage which contained numerical tasks, the second was a spreadsheet where participants had to write the results. The third was an interactive figure which showed the percentage of the solved and the remaining tasks.

For the VR group these three webpages were displayed next to each other, on a virtual board. For the web browser group, these were three different tabs next to each other. The participants had to solve these numerical tasks for five minutes then they had to fill out a questionnaire. In the questionnaire, they had to estimate their performance as the percentage of the completed and uncompleted tasks. They could do this only on the basis of the figure, as the number of all tasks was not mentioned anywhere. Thus the use of extra information could be measured also, besides the actual performance.

\section{Methods}

\subsection{Subjects}

Forty-nine healthy participants aged between 18 and 43 years old $(\mathrm{M}=25.2, \mathrm{SD}=$ 5.0), participated in the study. A between-subjects design was used, the two groups corresponded to the two different computer environments: MaxWhere VR 
$(\mathrm{N}=26)$ and Google Chrome browser $(\mathrm{N}=23)$. Pearson's $\chi 2$ test was used to determine if there is a significant difference between the expected frequencies and the observed frequencies in the two experimental groups (Table 1). Participants were randomly assigned to one of the two experimental conditions.

Table 1

Demographic characteristics and experimental variables organized by the experimental groups, and the results of Pearson's $\chi 2$ test

\begin{tabular}{|c|c|c|c|c|c|}
\hline & \multicolumn{2}{|c|}{$\begin{array}{l}\text { VR } \\
(N=26)\end{array}$} & \multicolumn{2}{|c|}{$\begin{array}{l}\text { Browser } \\
(\mathrm{N}=23)\end{array}$} & Result of Pearson's $\chi 2$ test \\
\hline Gender (\% of men) & \multicolumn{2}{|l|}{69.2} & \multicolumn{2}{|c|}{52.2} & $\chi 2(1, N=49)=0.863, p=0.353$ \\
\hline Measures & $\mathrm{M}$ & SD & M & SD & \\
\hline Age (in years) & 23.8 & 4.2 & 26.5 & 5.6 & $\begin{array}{l}\chi 2(16, \mathrm{~N}=49)=16.354, \mathrm{p}= \\
0.429\end{array}$ \\
\hline $\begin{array}{l}\text { Accuracy of } \\
\text { results (\%) }\end{array}$ & 96.77 & 4.63 & 96.73 & 4.16 & $\begin{array}{l}\chi 2(20, \mathrm{~N}=49)=22.233, \mathrm{p}= \\
0.328\end{array}$ \\
\hline $\begin{array}{l}\text { Estimation error } \\
\text { range (\%) }\end{array}$ & 12.37 & 16.02 & 13.78 & 12.64 & $\begin{array}{l}\chi 2(31, \mathrm{~N}=49)=33.944, \mathrm{p}= \\
0.328\end{array}$ \\
\hline
\end{tabular}

\subsection{Experimental Materials}

The participants of the experiments had to complete numerical tasks (e.g.: $24+7$ ), so the sum in their head and then write it into a spreadsheet. Each task was presented individually and they could load the next one with a click. The webpage of the tasks did not contain any numbering so the participants had no clue about the total number of tasks.

They had to write the results into a spreadsheet, into the same highlighted column under the previous one. The whole column was highlighted, so this did not help them in the estimation of performance.

The third webpage of the experiment was a graph, which showed the percentage of the solved tasks. This was automatically updated whenever the user registered a new solution to the spreadsheet. This graph was the only cue for the subsequent unheralded performance estimation.

The final questionnaire was always presented on the classic browser to all participants. Besides sociodemographic questions, they had to estimate their performance and then rank five factors, in the order of its influence on their estimation. They did not have to rank all factors, but they should mention at least one of them. 


\subsection{Apparatus and Software}

All participants completed the experiment on the same 14" laptop (LenovoYoga, 1920 x 1080px full HD display, 8 GB system memory, Nvidia GeForce 940 MX). All users used a computer mouse as a pointing device. All these features matched the system requirements of both used software.

\subsubsection{Google Chrome}

The most widely used web browser [31], Google Chrome was used in our experiment as a web browser. The three webpage of the experiment was displayed as three tabs, in the order of tasks, graph, and spreadsheet.

\subsubsection{MaxWhere Desktop VR}

The MaxWhere VR is a unique VR framework, which displays conventional web contents in a 3D virtual world. This VR environment was already used in several studies [7, 8, 10, 12, 32, 33, 34, 35, 36, 37]. Webpages (or pdf documents, images, video files from the PC) are presented on the so-called smartboards. These smartboards correspond to the tabs of a browser. When it is activated an address bar appears on the top to enable displaying any web content. Smartboards are in the standard 4:3 ratio or in A4 format for presenting documents. The MaxWhere VR environment has several "Where", what is the name of a predefined graphical and spatial design. The graphical design of the wheres are on a wide range from serene landscapes to modern offices or even spaceships. In addition, the wheres are designed for different purposes: there are educational (virtual lab for control theory) spaces, exhibition and conference spaces, collaboration or individual offices.

Cognitive Navigation and Manipulation (CogiNav) Method [38] is used to navigate in the 3D VR environment. This provides an intuitive way to move and perform operations with a simple external mouse.

In this study the InfoSky Where was used (artist: Tanaka, 3D modeling team), which is a relatively small space with twelve smartboards. The three webpage of the experiment was displayed on the top row of a $2 \times 3$ smartboard matrix (4:3 ratio), in the same order as the tabs were in the browser (tasks, graph, and spreadsheet). The informed consent was on the other side of the where, on an A4 smartboard.

\subsection{Procedure}

All participants were tested individually by the same experimenter. After a brief introduction about the experiment, they read and accepted the informed consent. 
Participants in the browser group started to solve the experimental task. They had five minutes to work on this, then they filled out the final questionnaire. The individuals in the VR group first entered in a tutorial Where to acquire the basics of the MaxWhere software and to practice the navigation. They could spend as much time as they needed with this trial. Then, they entered the InfoSky Where to start the experiment. They also had five minutes to solve the experimental task. Then, they also filled out the final questionnaire in Google Chrome browser.

\section{Results}

The objective of this study was to test the memory of supplementary information in desktop VR and in web-browser. During the experiment, the exact number of solved tasks, the estimation of the percentage of solved tasks were registered. Later all respondent's solutions were corrected, and the percentage of correctly solved tasks were calculated individually.

The main dependent variable was the estimation error, which was calculated as the absolute value of the difference between the exact and estimated performance. The smaller values mean more accurate estimation, thus they remembered better to the supplementary information.

The exact performance was not included in any statistical analysis, as its individual variability does not allow to draw conclusions about the differences of the workflow between the two groups. Accordingly, the perfect solution of the numerical tasks was not expected. On the average, the participants solved the tasks with the accuracy of $96.75 \%(\mathrm{SD}=4.42)$. Correlation with the estimation error was calculated $(\mathrm{r}(47)=0.104, \mathrm{p}=0.477)$, and it showed no significant relation between the two variables. Therefore, all data were included in further analysis irrespective of the accuracy of the performance on numerical tasks.

Some previous study found differences between male and female participants in complex virtual environment [22, 27]. As the Shapiro-Wilk normality test showed violation of normality (man: $W=0.677, p<0.001$; women: $\mathrm{W}=0.67, \mathrm{p}=0.001$ ), the Mann-Whitney rank test was used. No significant difference $(U=67.5, p=$ $0.824)$ were found between the performance estimation of men $(\mathrm{M}=11.94, \mathrm{SD}=$ 15.61) and women $(\mathrm{M}=13.31, \mathrm{SD}=16.86)$.

\subsection{Performance Estimations in VR and in Browser}

The VR group had a great advantage in the estimation of the performance as the graph of their performance was constantly visible thanks to the 3D arrangement. The members of the browser group had to switch to a third tab to be able to see this data. Thus, on average in the VR group, the estimation of performance should 
be more accurate. The normality was violated according to the Shapiro-Wilk normality test (browser: $\mathrm{W}=0.848, \mathrm{p}=0.003$; VR: $\mathrm{W}=0.676, \mathrm{p}<0.001$ ) so the Mann-Whitney test was used $(U=242, p=0.253)$. No significant differences were found between the estimation error of the VR and the browser group. Thus, despite the supposed advantage of the VR group, the average estimation did not differ between the two groups.

\subsection{Performance Estimations Based on the Graph}

Those who do not look at the performance graph at all were only guessing not really estimating. Those who indicated the graph as the main basis of estimation estimated more accurately their performance $(\mathrm{M}=6.62$, SD $=4.72)$ than those who do not $(\mathrm{M}=19.71$, $\mathrm{SD}=17.93)$.

Thus, by contrasting the results of those who indicated the graph as their main source of estimation, are more informative. Seven participants from the browser and eighteen from the VR group fall under the criterion of being in this subsample. Independent samples t-test was used to test whether the means are the same in the two groups. The results $\left(\mathrm{t}(23)=2.73, \mathrm{p}=0.012, \mathrm{~d}_{\mathrm{g}}=1.34\right)$ show significant difference between the two groups in this subsample (Figure 1). The mean of estimation errors was lower in the VR group $(\mathrm{M}=5.17, \mathrm{SD}=3.47)$ than in the browser group $(\mathrm{M}=10.36, \mathrm{SD}=5.39)$. In other words, the participants in the VR group estimated their performance more accurately.

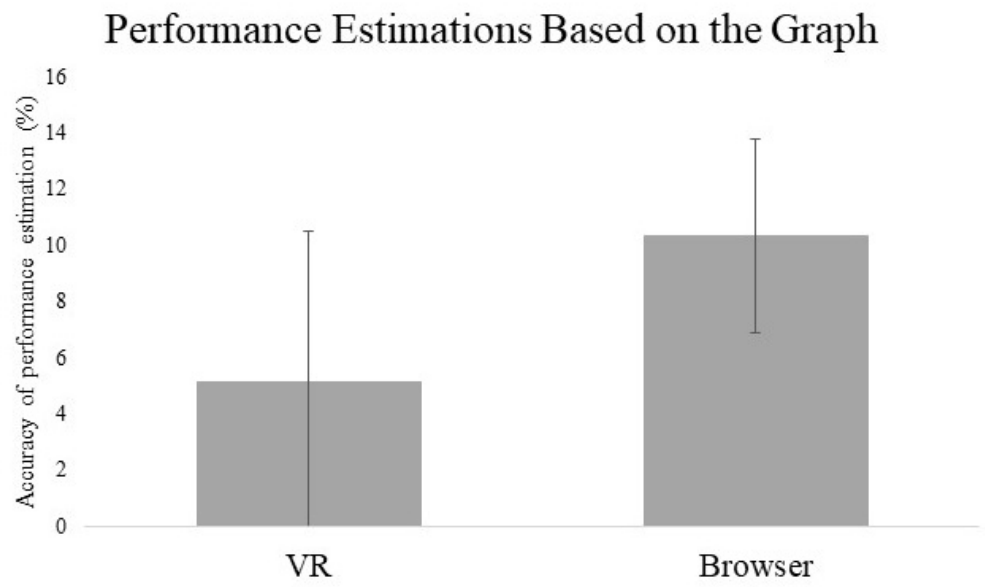

Figure 1

Error of performance estimation in the subsample of those who ranked the graph on the first place (the smaller values mean more accurate estimation; error bars represent the standard deviation) 


\section{Discussion}

With the visualization of extra information can a desktop VR provide extra benefits to its users? Can it offer more than a web-browser as a virtual workstation? The results of the current research could not show an overall positive effect with the use of VR, because the average estimation of the performance did not differ in the two groups. However, this hypothesized difference appeared within the subsample of those who indicated that their estimation was based on the graph. For those who paid attention to this information, the VR enabled a more effective use of information. Limitation of this study that there was not measured the duration when the participants looked at this piece of information. Thus, we cannot claim if this is a direct effect of the 3D virtual space or this benefit is mediated by the increased visibility of the information. A further research complemented by eye-tracking measures could answer this question.

This research showed that even on a more simple task, which requires only three different webpages, the desktop VR enabled a more effective application of the obtained information. Presumably, with more documents and more complex task, this difference would be even stronger and new differences would appear as the navigation would gain greater importance.

As shown above, the desktop virtual realities can serve as an effective virtual workspace which helps to expand the human cognitive capacities. It meets the previously described requirements of optimal workspaces, such as the use of less menu and more direct manipulation $[19,20]$ and providing the possibility to have a perspective and overview of the whole work [21]. To alternate between subtasks or different windows instead of switching, a more intuitive navigation is used, which simulate real-world movements of the body [22, 25, 26]. These movements can be realized with the help of such every day devices as an external mouse with a scroll wheel with the CogiNav method [38]. Moreover, the desktop virtual realities provide a wide range of collaboration tools and benefits, but these were not part of the current study.

\section{Conclusions}

The 3D desktop VR workspace provided an advantage to its users by displaying extra information permanently and individuals could use this information in their subsequent performance estimation.

\section{Acknowledgement}

This work was supported by the ÚNKP-18-3 New National Excellence Program of the Ministry of Human Capacities and by the FIEK program (Center for cooperation between higher education and the industries at the Széchenyi István University, GINOP-2.3.4-15-2016-00003). 


\section{References}

[1] S. K. Card, T. P. Moran and A. Newell, The Psychology of HumanComputer Interaction, New Jersey: Lawrence Erlbaum Associates Inc., 1983

[2] P. Baranyi and Á. Csapó, "Definition and Synergies of Cognitive Infocommunications," Acta Polytechnica Hungarica, Vol. 9, No. 1, pp. 6783, 2012

[3] P. Baranyi, A. Csapo and G. Sallai, Cognitive Infocommunications (CogInfoCom), Springer International Publishing, 2015

[4] J. Katona and A. Kovari, "EEG-based Computer Control Interface for Brain-Machine Interaction," International Journal of Online Engineering, Vol. 11, No. 6, pp. 43-48, 2015

[5] J. Katona and A. Kovari, "Examining the Learning Efficiency by a BrainComputer Interface System," Acta Polytechnica Hungarica, Vol. 15, No. 3, pp. 251-280, 2018

[6] K. Biró, G. Molnár, D. Pap and Z. Szüts, "The effects of virtual and augmented learning environments on the learning process in secondary school," in $8^{\text {th }}$ IEEE International Conference on Cognitive Infocommunications (CogInfoCom), Debrecen, 2017

[7] I. Horváth, "Disruptive technologies in higher education," in $7^{\text {th }}$ IEEE International Conference on Cognitive Infocommunications (CogInfoCom), Wroclaw, 2016

[8] I. Horváth, "Innovative Engineering Education in the Cooperative VR Environment," in $7^{\text {th }}$ IEEE International Conference on Cognitive Infocommunications (CogInfoCom), Wroclaw, 2016

[9] I. Horváth, "The IT device demand of the edu-coaching method in the higher education of engineering," in $8^{\text {th }}$ IEEE International Conference on Cognitive Infocommunications (CogInfoCom), Debrecen, 2017

[10] V. Kövecses-Gösi, "Cooperative Learning in VR Environment," Acta Polytechnica Hungarica, Vol. 15, No. 3, pp. 205-224, 2018

[11] Z. Kvasznicza, "Teaching electrical machines in a 3D virtual space," in $8^{\text {th }}$ IEEE International Conference on Cognitive Infocommunications (CogInfoCom), Debrecen, 2017

[12] B. Lampert, A. Pongracz, J. Sipos, A. Vehrer and H. Ildikó, "MaxWhere VR-Learning Improves Effectiveness over Clasiccal Tools of E-learning," Acta Polytechnica Hungarica, Vol. 15, No. 3, pp. 125-147, 2018 
[13] S. K. Card and D. A. Henderson Jr, "A multiple, virtual-workspace interface to support user task switching," in CHI '87 Conference on Human Factors in Computing Systems, Toronto, Canada, 1987

[14] D. A. Henderson Jr and S. K. Card, "Rooms: the use of multiple virtual workspaces to reduce space contention in a window-based graphical user interface," ACM Transactions on Graphics, Vol. 5, No. 3, pp. 211-243, 1986

[15] P. J. Spellman, J. N. Moiser, L. M. Deus and J. A. Carlson, "Collaborative Virtual Workspace," in Proceedings of the International ACM SIGGROUP Conference on Supporting Group Work: the Integration Challenge, 1997

[16] R. L. Daft and R. H. Lengel, "Organizational Information Requirements, Media Richness and Structural Design," Management Science, Vol. 32, No. 5, pp. 554-571, 1986

[17] A. Malhotra and A. Majchrzak, "Virtual Workspace Technologies," MIT Sloan Management Review, Vol. 46, No. 2, pp. 11-14, 2005

[18] A. Malhotra and A. Majchrzak, "How Virtual Teams Use Their Virtual Workspace to Coordinate Knowledge," ACM Transactions on Management Information Systems, Vol. 3, No. 1, p. 6, 2012

[19] T. M. Green, W. Ribarsky and B. Fisher, "Building and applying a human cognition model for visual analytics," Information Visualization, Vol. 8, No. 1, pp. 1-13, 2009

[20] M. Bricken, "Virtual Worlds: No Interface to Design," in Cyberspace: First Steps, M. Benedikt, Ed., Cambridge, Massachusetts: The MIT Press, 1991, pp. 363-382

[21] A. Endert, L. Bradel, J. Zeitz, C. Andrews and C. North, "Designing Large High-Resolution Display Workspaces," Proceedings of the International Working Conference on Advanced Visual Interfaces, pp. 58-65, 2012

[22] L. J. Ausburn, J. Martens, A. Washington, D. Steele and E. Washburn, "A Cross-Case Analysis of Gender Issues in Desktop Virtual Reality Learning Environments," Journal of STEM Teacher Education, Vol. 46, No. 3, pp. 51-89, 2009

[23] E. Peli, "The visual effects of head-mounted display (HMD) are not distinguishable from those of desk-top computer display," Vision Research, Vol. 38, No. 13, pp. 2053-2066, 1998

[24] B. S. Santos, P. Dias, A. Pimentel, J.-W. Baggerman, C. Ferreira, S. Silva and J. Madeira, "Head-mounted display versus desktop for 3D navigation 
in virtual reality: a user study," Multimedia Tools and Applications, Vol. 41, No. 1, pp. 161-181, 2009

[25] L. J. Ausburn and F. B. Ausburn, "Technical perspectives on theory in screen-based virtual reality environments: Leading from the future in VHRD," Advances in Developing Human Resources, Vol. 16, No. 3, pp. 371-390, 2014

[26] L. J. Ausburn and F. B. Ausburn, "Effects of desktop virtual reality on learner performance and confidence in environment mastery: Opening a line of inquiry," Journal of STEM Teacher Education, Vol. 45, No. 1, pp. 54-87, 2008

[27] L. J. Ausburn, F. B. Ausburn and P. J. Kroutter, "Influences of Gender and Computer Gaming Experience in Occupational Desktop Virtual Environments: A Cross-Case Analysis Study," International Journal of Adult Vocational Education and Technology, Vol. 4, No. 4, pp. 1-14, 2013

[28] E. A. L. Lee and K. W. Wong, "Learning with desktop virtual reality: Low spatial ability learners are more positively affected," Computers \& Education, Vol. 79, pp. 49-58, 2014

[29] "MaxWhere," [Online] Available: http://www.maxwhere.com/ [Accessed 26. 07. 2018.]

[30] Google Inc., "Google Chrome," [Online] Available: www.google.com/chrome/ [Accessed 26. 07. 2018.]

[31] StatCounter, "Desktop Browser Market Share Hungary," 2018 [Online] Available: http:/gs.statcounter.com/browser-marketshare/desktop/hungary. [Accessed 26. 07. 2018.]

[32] B. Berki, "2D Advertising in 3D Virtual Spaces," Acta Polytechnica Hungarica, Vol. 15, No. 3, pp. 175-190, 2018

[33] T. Budai and M. Kuczmann, "Towards a Modern, Integrated Virtual Laboratory System," Acta Polytechnica Hungarica, Vol. 15, No. 3, pp. 191-204, 2018

[34] G. Csapó, "Sprego virtual collaboration space: Improvement guidelines for the MaxWhere Seminar system," in $8^{\text {th }}$ IEEE International Conference on Cognitive Infocommunications (CogInfoCom), Debrecen, 2017

[35] G. Bujdosó, O. C. Novac and T. Szimkovics, "Developing cognitive processes for improving inventive thinking in system development using a collaborative virtual reality system," in $8^{\text {th }}$ IEEE International Conference on Cognitive Infocommunications (CogInfoCom), Debrecen, 2017 
[36] A. Gilányi, G. Bujdosó and M. Bálint, "Presentation of a medieval church in MaxWhere," in $8^{\text {th }}$ IEEE International Conference on Cognitive Infocommunications (CogInfoCom), Debrecen, 2017

[37] I. Horváth and A. Sudár, "Factors Contributing to the Enhanced Performance of the MaxWhere 3D VR Platform in the Distribution of Digital Information," Acta Polytechnica Hungarica, Vol. 15, No. 3, pp. 149-173, 2018

[38] P. Baranyi, P. Galambos, Á. Csapó and L. Jaloveczki, "Cognitive Navigation and Manipulation (CogiNav) Method". U.S. Patent 15/658,579, 2018 